\title{
Segurança e defesa: uma única visão abaixo do Equador ${ }^{* 1}$
}

\section{DARC COSTA**}

Inicialmente, antes de entrar na discussão do tema que nos foi proposto: "defesa e segurança: as posições brasileira e argentina”, cumpre ressaltar que procuraremos construir, como o próprio título do artigo adianta, uma visão que contemple mais além do que o simples olhar atual, individual e compartimentado da segurança e da política de defesa nacional do Brasil e da Argentina. Buscaremos imaginar uma visão de segurança comum no Mercosul e uma política comum de defesa, para ambos os países.

Esta postura nos parece ser a resposta correta ao processo de transformação recente da economia mundial, descrito como de globalização, mas que mais apropriadamente se colocaria, em nossa opinião, como polarização e que está sendo correspondido no campo político pela criação de pólos de poder, como a União Européia. Existe uma polarização econômica travestida de regionalização. Hoje, ter poder e ser centro exige escala; e países pequenos ou se unem em mercados maiores, Megaestados, como é o caso da União Européia, ou estão fadados a se tornar ou permanecer periféricos.

Acresce-se a esta colocação uma outra constatação, presente neste texto, de que o Brasil e a Argentina, juntos, devido a sua atual posição periférica no campo político no cenário mundial, estão geograficamente destinados a subpolarizar e a liderar a formação de um pólo de poder na América do Sul, fruto da cooperação sul-americana.

Antes de avançar no tema proposto, é sempre bom lembrar que segurança é um estado e defesa é um ato. Por isso, as questões relativas à segurança devem sempre preceder ao estabelecimento de uma política de defesa. Esta, também, deveria ser a ordem proposta para o tema: segurança e defesa e não defesa e segurança. Primeiro, é preciso estabelecer as bases sobre as quais se possa assentar a segurança da nação, ou das nações e de seus cidadãos. Depois, pensar em como se defender, caso estas bases sejam ameaçadas de rompimento.

Outra questão preliminar reside no fato de que a segurança e a defesa de qualquer país são, antes de tudo, uma questão de natureza estratégica. Não são,

Rev. Bras. Polít. Int. 42 (1): 127-156 [1999]

* Texto cedido para publicação pelo Instituto de Pesquisa de Relações Internacionais - IPRI, Ministério das Relações Exteriores.

** Professor da Universidade Federal do Rio de Janeiro e da Escola Superior de Guerra. 
portanto, do tipo de temas capazes de ter uma apresentação livre de metodologia. Existe, consagrada, uma metodologia para a avaliação de uma situação estratégicomilitar que, pela sua própria natureza, se aplica, perfeitamente, ao estudo de questões que dizem respeito à segurança e à defesa. Esta é a metodologia que nos acompanhará e seu desdobramento metodológico é o que se segue:

- $\quad$ interpretação e avaliação da missão que, no caso proposto, consiste em uma política de defesa para o Brasil, para a Argentina, logo, também, para o Mercosul;

- $\quad$ explicitação e análise das ameaças que pesam ou pesarão sobre o Brasil, sobre a Argentina e sobre o Mercosul;

- $\quad$ análise dos meios para a defesa, disponíveis ou mobilizáveis;

- $\quad$ escolha de uma estratégia para a defesa de ambos os países e de espaços comuns de interesse; e

- conclusões e recomendações.

\section{1) Interpretação e avaliação da missão}

Ao iniciarmos o estudo, devemos entender qual o objetivo do mesmo, que é o de prover segurança e política de defesa a um amplo espaço abaixo do Equador, que engloba muito mais que o território continental das duas nações: o Brasil e a Argentina.

Fixar os contornos da segurança para este espaço; buscar o estabelecimento de política de defesa para cada um e conjunta, para ambos os países; envolve assinalar as principais características que venham a influenciar a dinâmica política, econômica e psicossocial dos dois países, diante dos desafios mundiais. Para tanto, é de fundamental importância avaliar a evolução tanto da conjuntura mundial, a partir do quadro atual de poder, quanto se apresentar, em sua real dimensão, a abordagem atual da segurança e da defesa no Brasil e na Argentina.

1.1) O quadro atual de poder e a provável evolução da conjuntura mundial

Iniciemos analisando o atual quadro de poder e sua provável evolução. Como sempre, este quadro traz em si a permanente dualidade: o centro e a periferia. O centro composto de três atores, o núcleo hegemônico, que conceituamos como os EUA, e os núcleos não hegemônicos, composto, na nossa visão, pelo Japão e pela União Européia. A periferia imaginamos como sendo todo o resto, mas também dividida entre periferia polarizadora e periferia polarizada, como veremos adiante. Tanto o Brasil, como a Argentina fazem parte da periferia.

Como premissa inicial da conjuntura que vivemos, afirmamos que, com o término da Guerra Fria, há dois processos em marcha: 
- o primeiro processo decorre de que se voltou a priorizar, como parte determinante da equação política, as questões econômicas internacionais (com o fim da bipolaridade, a segregação das questões econômicas ou a subordinação delas ao campo ideológico deixou de existir, assim como desapareceu a estranha urdidura que as colocava como praticamente apolíticas. Os homens lutaram por questões econômicas no passado e tudo indica que voltarão a lutar por essas questões no futuro);

- $\quad$ o segundo processo, que decorre da regionalização da vida econômica, é a emergência de potências políticas regionais como forças que procurarão, crescentemente, a independência e que se posicionarão, permanentemente, em busca de uma melhor posição mundial.

Estabelecidos estes pressupostos, cabe-nos apresentar a atual situação mundial, o que faremos, de forma resumida e simplificada, por um modelo esquemático. Este modelo compõe-se de um centro, como já colocamos, composto de três núcleos que se movimentam na busca da dominação - onde um exerce a hegemonia, como também já foi colocado -, cercado de diferentes e diversas periferias, também móveis e atuantes, que buscam de forma conflitiva fazer parte deste núcleo. Este centro encontra-se em expansão, por uma progressiva polarização em torno do núcleo hegemônico: os EUA, via NAFTA, e dos dois outros núcleos não hegemônicos: a Alemanha, pela constituição da União Européia, e do Japão, pela constituição de um círculo de interesses na Ásia, que batizaremos de Complexo Asiático. Na periferia, alguns movimentos de articulação se processam, dentre estes, a formatação de subpolarizações, como a que une Brasil e Argentina no Mercosul.

Analisaremos neste modelo a sua possível evolução futura. Para tanto, dividimos nossa análise em cinco visões: a do núcleo hegemônico, a dos núcleos não hegemônicos, a da periferia, a que eles todos têm de nós, Brasil e Argentina, e a nossa visão de nós.

\subsection{1) A visão do núcleo hegemônico}

Alguns analistas afirmam que não existe, hoje, um Estado claramente hegemônico. Contudo, para nós, a posição americana no mundo é de centro e de núcleo hegemônico. Não só os Estados Unidos detêm um poder militar incontrastável, como exercem a liderança econômica do mundo, decorrente de deterem a moeda internacional, o dólar, e uma posição competitiva favorável. Como os estrategistas dos Estados Unidos olham o futuro?

Existe quase um consenso, ao final do século XX, no pensamento estratégico dos EUA, de que a sua situação hegemônica indiscutível é uma situação passageira e que em 15, 30, ou, no máximo, em 50 anos, a estrutura de poder mundial voltará a um clássico modelo multipolar. É quase consenso entre os maiores pensadores 
em estratégia norte-americanos que haverá, no futuro, uma perda progressiva de poder dos Estados Unidos, na arena mundial. Estes maiores pensadores diferem, contudo, profundamente, no modo pelo qual os americanos se defrontarão com o novo contexto.

Três são as correntes que tratam deste reposicionamento, melhor dizendo, dessa futura decadência:

A primeira, que nomearemos como a dos fatalistas, que coloca que nada poderá ou deverá ser feito e encontra a sua formulação mais forte na obra The Rise and Fall of the Great Powers, de Paul Kennedy. Partindo de uma visão que se apoia em uma análise pretérita histórica, os fatalistas colocam que a própria posição hegemônica norte-americana conduz a imensos gastos para a manutenção desta situação, em especial, gastos militares, e isto, progressivamente, comprometerá as finanças públicas americanas e conduzirá à perda crescente de poder dos Estados Unidos no panorama mundial.

A segunda, que nomearemos como a dos ativistas, que coloca que algo poderá ser feito e encontra sua melhor versão na obra Diplomacy de Henry Kissinger, que afirma ser possível uma postura ativa que, aceitando a inexorabilidade da queda, postula-a como passível de ser controlada com ações de curto prazo, algo que melhor seria traduzido como participar quando puder e do melhor jeito que puder.

A terceira, que nomearemos dos articulistas, que defende que muito poderá ser feito e que tem seu melhor texto na obra Out of Control: Global Turmoil on the Eve of the Twenty-First Century, de Zbigniew Brzezinski, antigo membro do Governo Carter, e que afirma que, dada a não possibilidade de evitar a queda, os Estados Unidos precisam fazer uma retirada estratégica, procurando organizar o mundo, para uma era pós-Pax Americana, que teria como seu grande legado um sistema global de equilíbrio geopolítico auto-sustentável.

É verdade que a primeira destas visões está muito mais próxima que as demais da idéia da guerra como o ato final da ruptura. Sua própria característica pressupõe um progressivo esvaziamento de poder decorrente do esforço econômico; todavia, o próprio final, a ruptura, resulta, como a análise histórica pretérita procedida demonstra, de um esforço de guerra.

As outras visões repõem, de forma nova, a clássica dicotomia presente na visão americana de mundo, em que se opõem, há cem anos, os intervencionistas aos isolacionistas. Seria muito primitivo atribuir-se a Kissinger uma visão intervencionista no modelo do walk softly and carry a big stick (ande suavemente e carregue um grande porrete), mas é indubitável a sua inteira subordinação ideológica ao que os alemães chamam de realpolitik, ou seja, à idéia que os Estados Unidos têm de ser fortes e atuantes e que sua política deverá ser global e pautada pelo interesse nacional. Assim, também, poderia parecer despropositado vincularse Brzezinski àqueles que defendem a tese de que a política externa norte-americana 
deve ser exclusivamente baseada em princípios morais. Entretanto, é óbvio, no texto deste autor, que é do exemplo que a democracia americana tira sua principal força. Contudo, essas visões são análises próprias, de nossa época, das duas correntes que dividem o modo de ver o mundo dos norte-americanos e que, apesar de se apoiarem em premissas diferentes, não afastam a hipótese de guerra e justificam a necessidade de generosas despesas militares no orçamento dos Estados Unidos. Aliás, é bom lembrar que os Estados Unidos, mergulhados no passado, nos ditames de uma ou de outra corrente, caminharam, diversas vezes, inexoravelmente, para situações de guerra.

Contudo, uma das análises publicadas, presente na obra The Clash of Civilizations and The Remaking of World Order de Samuel Huntington, que teve ampla divulgação nos círculos intelectuais norte-americanos, rompe com o quase consenso da inexorabilidade da decadência ao apresentar a possibilidade da manutenção da hegemonia norte-americana como o centro de um esquema de poder dominante, composto basicamente pelos Estados Unidos e pela União Européia. Nesta visão prospectiva, o conceito da guerra encontra-se, também, claramente presente e opõe o que o autor conceitua como efetivamente civilizado, os europeus e os norte-americanos, a uma ou a várias barbáries, que se estruturam como outras formas de civilização. Apesar de destoante da maioria dos pensadores, a proposta de Huntington, pela sua posição otimista, é a que merece o maior apreço e destaque da mídia e da opinião pública norte-americanas.

Encontramo-nos, portanto, e aí existe um total consenso de todas as correntes formadoras da estratégia dos Estados Unidos, muito longe das visões irreais de inação do Estado nacional postas por Immanuel Kant em Perpetual Peace ou por Karl Marx em Withering Away of State, e mais recentemente por Lord Williams Rees-Mogg, em sua obra The Sovereign Individual. Nesta obra, este autor chega a afirmar que os Estados nacionais perderão sentido e que os conflitos deixarão de ser guerras nacionais e se darão no âmbito de relações no interior da sociedade civil. O conceito da guerra entre Estados nacionais é uma constante na visão da geopolítica, do trato do poder e da estratégia norte-americana.

Posta a inevitabilidade do conflito armado, cabe-nos questionar quais seriam os interesses vitais dos Estados Unidos que os mobilizariam a ponto de se defrontarem, militarmente, com competidores, cujo tempo, inexoravelmente, fará aumentar em número e em poder. Será vital o controle das principais passagens marítimas do mundo? Será fundamental o suprimento de petróleo? O controle do mercado asiático é uma questão de prioridade estratégica?

Para responder estas perguntas cabe observar quais os desdobramentos passados da bem sucedida estratégia nacional dos Estados Unidos, pois eles configuram o círculo de interesses que arquitetou a sua hegemonia atual. Qualquer estudioso verifica que a estratégia perseguida pelos norte-americanos foi aquela tão brilhantemente sintetizada na obra The Coming War with Japan, de George 
Friedman e Meredith Lebard, que estabeleceu como os seguintes os patamares estratégicos perseguidos pelos norte-americanos desde a sua independência:

- $\quad$ "que o poder e o exército dos EUA dominem de forma completa a América do Norte;

- $\quad$ que não exista nenhuma potência ou grupo de potências no hemisfério ocidental capaz de contestar a hegemonia dos EUA;

- $\quad$ que a marinha dos EUA seja capaz de manter as potências do hemisfério oriental fora do hemisfério ocidental, através do controle do Atlântico Norte e do Pacífico Leste;

- $\quad$ que nenhum poder do hemisfério oriental possa desafiar o domínio norteamericano dos oceanos, desviando suas energias para ameaças terrestres."2

Esta macroestratégia, tão bem resumida e explicitada, é totalmente respaldada na leitura da obra central da formulação da ação norte-americana, ao longo da II Grande Guerra, America's Strategy in World Politics, de Nicholas Jonh Spykman. Conforme se depreende da leitura desta obra, o desafio estratégico norte-americano esteve e está posto a nível global.

Assim sendo, aonde estarão os possíveis contestadores? Quais serão suas ações? Qual é a ação preventiva dos EUA e quais suas possíveis reações?

Comecemos respondendo à última destas questões. Em recente artigo publicado na revista Foreign Affairs, intitulado "How America Does It”, Josef Joffe faz uma detalhada análise que responde qual tem sido a ação estratégica preventiva norte-americana e que pode ser assim resumida: os EUA, hoje, prioritariamente colocam como objetivo central de sua ação política internacional manter seu atual sistema de alianças e o regime de livre comércio como sistema permanente de controle internacional. Isto poderá vir a ser feito, até mesmo, através da transformação de seu sistema de alianças em um sistema imperialista, usando seu poderio atual, inclusive o militar, para manter sua hegemonia, tanto no seu sistema de alianças, como no antigo bloco soviético e, também, no antigo terceiro mundo.

Entretanto, os EUA poderiam ter, amanhã, outro posicionamento e vir a dar prioridade a isolar-se em seu hemisfério, criando um bloco político e econômico no hemisfério ocidental, utilizando a sua marinha para manter o domínio dos oceanos, evitando intervenções francas no hemisfério oriental, a menos que uma única potência ameace esta hegemonia, e usando o seu controle dos oceanos para manipular o comércio marítimo mundial, de forma a evitar que tal potência venha a surgir.

Ambas as possibilidades devem ser merecedoras de total atenção para os formuladores da segurança e de política de defesa no Brasil e na Argentina.

Contudo, há um ponto que nos parece óbvio e tem figurado, explicitamente, nas análises dos interessados em prever o comportamento futuro dos Estados Unidos. Este ponto é o fato dos EUA não se imaginarem contestados no próprio 
continente americano. Aqui está um ponto central deste trabalho. Todos os seus possíveis contestadores sempre são vistos no hemisfério oriental. Para os norteamericanos, a sua hegemonia incontestável no continente americano é algo fundamental, acima de todos os demais interesses, como já o foi no passado (que os digam as suas diversas intervenções militares no continente americano, neste século) e é, e será, certamente, o mais forte motivo para um novo engajamento militar em uma nova guerra, por parte dos Estados Unidos. Repetimos, esta é uma fortíssima questão presente ao se abordar aspectos de segurança e de política de defesa para o Brasil, para a Argentina e para o Mercosul.

Dado o peso dos Estados Unidos no comércio mundial, é interessante, também, fazermos algumas considerações quanto à sua política comercial, cujas diretrizes estão claramente expressas na sua Lei de Comércio e Tarifas, de outubro de 1984. Essa lei procura ser abrangente, já que tenta integrar objetivos diversos, relacionados ao comércio de bens, serviços, investimentos externos e transferências de tecnologia. Envolve processos de negociação, bilateral e multilateral, consultas e retaliações. Cabe ressaltar que um dos objetivos da lei é dar, ao presidente dos EUA, poderes para impor restrições de acesso ao mercado norte-americano de bens, mesmo que a questão que tenha gerado contencioso diga respeito a investimento, tecnologia e serviços. Neste campo, também, a estratégia do governo norte-americano tem sido de buscar a liberalização completa nas transações onde sua economia aparentemente tenha vantagens comparativas. Seu posicionamento, em diversos foros e, em particular, na Rodada Uruguai do GATT, e agora na Organização Mundial do Comércio, consubstancia essa formulação, decorrente da filosofia econômica que adota. Está claro que, mesmo antes daquela rodada de negociações, os EUA passaram a exigir mais esforços dos países em desenvolvimento, que tiveram perda significativa do tratamento especial de que se beneficiavam. Tal ação se faz sentir com maior reflexo sobre a América Latina, que tem procurado, de forma tíbia, adequar suas políticas econômicas à nova realidade do comércio internacional.

No campo político, estratégico e militar, os EUA buscam consolidar sua área de poder, para influir em soluções condizentes com seus interesses nos conflitos que se deflagram no mundo. Buscam, ademais, ações diretas para evitar o acesso a terceiros das chamadas armas de extermínio de massa. Esta é, em resumo, a estratégia do país dominante no centro atual.

\subsection{2) A visão dos núcleos não hegemônicos}

Vários analistas admitem a ausência, no momento atual, de predomínio dos Estados Unidos no campo econômico e preferem ver a existência de uma multipolaridade econômica competitiva, que envolveria os Estados Unidos, a 
Alemanha e o Japão. Como afirmamos antes, o que fica claro é a existência de um processo de polarização econômica, tecnológica e financeira, que envolveria estes três países, o centro, essa "tríade", ou para alguns, a trilateral.

Todavia, tanto a Alemanha como o Japão não possuem a estatura política condizente com seu atual estágio econômico. Militarmente, tanto a Alemanha como o Japão encontram-se ainda ocupados por tropas norte-americanas, passados mais de 50 anos do término da II Grande Guerra e dez anos do término da Guerra Fria. Politicamente, ambos os países continuam fora do condomínio político exercido pelos membros permanentes do Conselho de Segurança das Nações Unidas

Os objetivos centrais da ação estratégica nacional destes dois países é o de recolocar as suas estaturas políticas na verdadeira grandeza de suas estaturas econômicas. Seguem estratégias diversas, mantendo, todavia, ambos os países, um sistema de poder nacional em que enfatizam o relacionamento entre o grande capital privado, o Estado nacional, o desenvolvimento de tecnologia, as Forças Armadas e a sociedade civil. Tanto um como outro não alteraram sua concepção estratégica básica, que se formatou no século passado.

A concepção estratégica da Alemanha era e é clara: o domínio da Europa Continental, daí o domínio da Europa e da Ásia e do Mundo. O que mudou em sua estratégia foram os meios a serem utilizados, que de militares tornaram-se econômicos. Foi economicamente que a Alemanha conseguiu a reunificação e é economicamente que a Alemanha tem buscado, com sucesso, o domínio da Europa. A União Européia é, antes de tudo, um projeto alemão. É, ainda, economicamente que a Alemanha buscará dar seu maior passo estratégico, o euro, a contestação do dólar.

As prioridades alemãs em termos de política externa encontram-se na Eurásia, em especial, na Europa Oriental. Os estrategistas europeus, especialmente os alemães, advogam uma maior proximidade operativa com a Rússia, algo que só poderá avançar com a consolidação da União Européia. Existe no imaginário alemão, no espaço europeu, uma outra figura, e esta figura tem assento permanente no condomínio político: a Rússia.

Já o Japão, possui uma concepção estratégica limitada, que se resume ao domínio das margens da Bacia do Pacífico. A derrota militar da II Grande Guerra marcou profundamente a sociedade japonesa que, agora, busca exercer este domínio, também, por meios econômicos. Os dois movimentos externos dominantes na política externa japonesa, a chamada política dos gansos voadores, ou seja, a conquista dos mercados do Leste Asiático, tanto pela implantação de indústrias tradicionais neste espaço como pela reserva destes mercados para os produtos japoneses, e a chamada política do tubarão amarelo, para a costa do Pacífico do hemisfério ocidental, que busca aumentar a presença econômica japonesa na costa oeste dos Estados Unidos, no México, no Peru e no Chile, reforçam esta colocação. Aqui, também, existe uma outra figura. Os estrategistas japoneses, entendem que o Japão só avançará efetivamente na busca de seu objetivo se fizer uma maior 
aproximação com a China, outro membro do condomínio político do Conselho de Segurança das Nações Unidas.

Daí porque é importante para as duas diplomacias, tanto a japonesa como a alemã, a reforma do Conselho de Segurança que, antes de permitir o seu ingresso no ambicionado condomínio político, é a demonstração cabal das composições da Alemanha com a Rússia e do Japão com a China, composições estas, necessárias, na visão de seus estrategistas, para repor estatura política aos dois países.

Há, em ambas as visões, a clara percepção de que, enquanto não solucionada a questão da estatura política, a melhor conduta no campo econômico, político e militar é de procurar não contestar, objetivamente, os desígnios dos norteamericanos. Daí o porque do apoio às iniciativas norte-americanas, no âmbito das organizações internacionais. $\mathrm{O}$ apoio a estas iniciativas tem se materializado nos foros como a OCDE e a OMC, na elaboração de normas, na aprovação do mecanismo de "condicionalidades" imposto pelo FMI e pelo Banco Mundial aos países endividados e em crise e até nas sanções impostas pela ONU ao Iraque.

Pode parecer, contudo, que, subjacente a tudo isto, exista uma certa concordância com o antigo esquema do geopolítico alemão Haushofer de divisão do mundo, em que uma tríade assumiria oligopolisticamente o controle do poder mundial, dividindo claramente seus mercados, algo que não tem mais tanto respaldo e perdeu conteúdo nesta virada do século XX para o século XXI. Esta concordância não existe, por parte dos americanos, nem por parte dos alemães, nem por parte dos japoneses. Todos têm uma visão própria de mercado mundial.

\subsection{3) A visão da periferia}

A periferia no modelo apresentado é tudo que não pertence ao centro e se constitui de Estados que, para simplificar, podem seguir duas possíveis classificações: quanto ao potencial e quanto ao comportamento.

Na classificação referente ao potencial, os Estados se dividem em polarizadores e polarizados. Os Estados polarizadores são aqueles que, por terem grande população e uma economia emergente, são capazes de constituir mercados dinâmicos, permitindo processos que levam à economia de escala, em especial, nas chamadas áreas de tecnologia de ponta. Os Estados polarizados são aqueles desprovidos daquele atributo e destinados a compor, em decorrência de sua posição geográfica, com outros Estados, e/ou com algum Estado polarizador dentro de um processo mundial de crescente regionalização, um Megaestado. Os Estados polarizadores mais evidentes são a China, a Rússia, a Índia, a Indonésia e o Brasil.

Na classificação referente ao comportamento, os Estados se dividem em Estados pertubadores e Estados subordinados. Os Estados perturbadores são aqueles que se insubordinam contra os ditames do centro e os Estados subordinados são aqueles que seguem os ditames políticos do centro. Há diferentes graus de 
perturbação, mas, como perturbadores radicais podemos citar a Coréia do Norte, o Iraque e o Afeganistão. Toda periferia tem em si algum grau de contestação que se explicita em perturbação, mas é inegável que, atualmente, a Áustria e o México são Estados subordinados.

A História Universal nos mostra que, para um Estado periférico chegar ao centro, ele tem de ser perturbador. Hoje, para se chegar ao centro, também, tem-se de ser polarizador. Estas duas condições criam a possibilidade de um Estado periférico vir a ser centro.

Na periferia, os Estados polarizadores com maior grau de liberdade econômica são, nessa ordem: a China, a Índia e a Rússia.

Na periferia, os Estados polarizadores que, geograficamente, possuem maiores graus de liberdade são o Brasil, a Indonésia e a Índia, pois são os que estão mais espacialmente afastados dos atuais núcleos do centro. Destes, a Índia é a que possui atualmente o maior grau de contestação. Contudo, a Índia, como a Indonésia, tem restrições geográficas ao papel de polarizador. A Índia, por se situar em um pedaço restrito de um continente, a Península Indiana, e a Indonésia, por se situar em um arquipélago, têm sérias dificuldades na sua função de polarizador, ou seja, na constituição de um espaço geográfico único com demais Estados para a constituição de um Megaestado. Este não é caso do Brasil, que detém condições geográficas excepcionais de polarizar, não tanto por ser um Estado dotado de fronteiras com diversos outros Estados, em um subcontinente periférico, a América do Sul mas, principalmente, por contar, nesse processo de polarização, com um parceiro e vizinho com o gabarito geográfico e demográfico da Argentina. Há mesmo, na América do Sul, a possibilidade da formação de um binômio BrasilArgentina de natureza análoga ao binômio Alemanha-França que constituiu o fulcro de articulação da União Européia, algo que pela sua grandeza, não se repete em nenhuma outra parte do planeta.

Cabe-nos apresentar aqui, e de forma rápida, a concepção estratégica dos Estados mais relevantes da periferia. A China tem como objetivo central de sua concepção estratégica restaurar seu território nacional pela unificação com a China insular: Taiwan. A concepção estratégica chinesa é muito limitada, mas vem sendo transformada, nos últimos anos. Já a Rússia, tem uma elaborada e complexa concepção estratégica que pressupõe como estabelecido pelo seu formulador Pedro, o Grande, o domínio da Eurásia. Contudo, a Rússia de Yeltsin não é contestadora. É subordinada e apaziguadora como se pode ver pelo seu comportamento nas questões relativas aos Balcãs. Sua estratégia tem sido a de procurar uma aliança com a China, pois se sente ameaçada pela conjunção de interesses entre os EUA e a União Européia. Contudo, caso se consiga solucionar a questão balcânica, dadas a posição geográfica da Rússia e a concepção estratégica da Alemanha, é somente uma questão de tempo a prevalência de um pensamento pró-europeu na Rússia. 
Deve sempre estar presente, na formulação da estratégia nacional, na periferia, o fato de que a montagem de alianças estratégicas de Estados polarizadores entre si, ou com os núcleos não hegemônicos do centro, é o melhor caminho a ser seguido para o exercício da função pertubadora à ordem internacional no caminhar de um Estado para o centro.

\subsection{4) A visão deles do "abaixo do Equador"}

O núcleo hegemônico, os EUA, tem consciência da realidade, ou seja, que nós, Brasil e Argentina, nos inserimos na sua mais importante área estratégica: a América. Tem consciência de que é fundamental para sua hegemonia a sua dominação sobre o espaço americano. Pode-se resumir que, no momento, a ação do núcleo hegemônico é, no campo político, a de garantir que os governos brasileiro e argentino mantenham uma posição se não alinhada, pelo menos não contestatória aos seus desígnios para o hemisfério. Já no campo econômico, sua ação é a de buscar nos inserir, mediante a criação da Área de Livre Comércio para as Américas (ALCA), de forma plena e definitiva, em seu espaço de dominação, em sua polarização. Com isto o centro hegemônico pretende:

a) a permanência, no Brasil, na Argentina e nos demais países das Américas, de regimes políticos que melhor assegurem a defesa dos seus interesses políticos e econômicos;

b) garantir a imposição de sua cultura sobre a cultura brasileira, a cultura argentina e a dos demais povos do Hemisfério Ocidental;

c) promover sua visão de mercado através de um sistema que articule suas universidades como centros fornecedores de treinamento profissional para prováveis integrantes das futuras elites dos demais países das Américas, em especial, do Brasil e da Argentina;

d) implantar um sistema econômico nas Américas, cujas normas garantam maior liberdade de circulação dos seus fatores de prevalência - o capital, bens e serviços -, mas que excluam o fator trabalho;

e) dar maior capacidade de proteção a setores da economia norteamericana ameaçados de competição dentro e fora do continente, pela adição de mercados dos outros países das Américas ou mediante a criação de barreiras de defesa de seu mercado;

f) induzir os demais Estados, nas Américas, a adotar procedimentos jurídicos, normas de atividade, instituições e políticas econômicas condizentes e semelhantes às norte-americanas;

g) garantir o acesso americano diretamente às fontes de matéria-prima existentes no continente, imprescindíveis ao desenvolvimento da economia norteamericana, em especial de bens energéticos; 
h) inibir o aparecimento no continente de pólos de tecnologia, fora do seu controle, de modo a impedir o surgimento de competidores efetivos nos mercados de ponta mais lucrativos.

O objetivo central do núcleo hegemônico para o Brasil, para a Argentina, bem como para os demais países da América, é conhecido como "Consenso de Washington" e tem como principal objetivo manter os mercados destes países abertos para as suas exportações através da defesa infatigável das teorias econômicas liberais, em especial das vantagens comparativas, de especialização primária agrícola e mineral, e do livre comércio.

Os núcleos não hegemônicos, a Alemanha e seus parceiros da União Européia e o Japão, têm uma estratégia diferente do núcleo hegemônico para o Mercosul e os demais países da América. Apesar de, nos foros internacionais, fazerem coro com o discurso dos EUA, buscam, em paralelo, construir na região uma base industrial, com filiais de suas empresas transnacionais, ou com seus capitais, capazes de garantir mercado para seus produtos ou sua tecnologia. $\mathrm{O}$ Mercosul, e dentro deste o Brasil, é, neste esforço, o objetivo central da União Européia. Entendem que, nessa região, podem vir a desestabilizar o predomínio econômico mundial norte-americano, pois imaginam que criando uma nova polarização no Hemisfério Ocidental estariam interferindo no espaço de maior interesse dos EUA. Para ambos os núcleos não hegemônicos, o Brasil, a Argentina e o Mercosul têm extrema importância nas relações que eles podem vir a ter com os EUA, além de apresentar um enorme potencial.

A periferia vê o Brasil como um polarizador subordinado e vê a Argentina como um parceiro do Brasil na arena internacional, mas um parceiro que reforça a postura brasileira de subordinação. Contudo, como a China, a Rússia e a Índia colocam nos seus centros de pensamento estratégico, para nós existe espaço para uma possível contestação, para exercermos a perturbação, algo que, na visão deles, nos daria as condições para rapidamente vir a ser centro. Será que o seremos no futuro? Será que perturbaremos? Se o fizermos, imaginam ser possível o nosso sucesso, ou, pelo menos, a minimização da hegemonia atual, algo que demonstram ter grande interesse. Daí porque a vontade, em especial dos chineses, na montagem com o Brasil e a Argentina de parcerias ou alianças estratégicas.

\subsection{5) A nossa visão do "abaixo do Equador"}

A partir de meados da década de oitenta, gerou-se, abaixo do Equador, progressivamente, um jogo de interesses cruzados, que, paulatinamente, conduziram a uma crescente interdependência entre: Brasil e Argentina. Esta interdependência progressiva levou os atores privados e públicos a constituírem um mesmo cenário político, o Mercosul. 
O Mercosul, como instituição política, transformou-se institucionalmente em um elemento de estabilidade e, pelos interesses que vem gerando, é um poderoso instrumento de combate a qualquer possível fragmentação na região.

Criou-se, portanto, um novo contexto, onde a velha visão do vizinho como adversário e ameaça a nossa segurança foi superada pela constatação de que os riscos do vizinho agora são nossos próprios riscos. O Mercosul transformou o Brasil e a Argentina em irmãos siameses, unidos pelos interesses de um mercado de escala e apartados, geograficamente, das rotas de comércio mundial. Não há mais caminho para o centro sem a união cultural, econômica, política, militar e social que o Mercosul proporciona.

Acresce a essa constatação o fato de que foi e é necessário ir além, ampliando o espaço comum pelo envolvimento de outros parceiros no processo de integração e cooperação, como foi o caso de Uruguai e Paraguai, em 1991 e de Chile e Bolívia, em 1996.

Nós somos mais que próximos. Somos vizinhos, além de estarmos ambos geograficamente deslocados dos caminhos centrais do comércio mundial. Somos ibero-americanos. Isto a hegemonia não alterará, pois se trata da própria natureza das coisas e nos vemos assim.

Estas visões configuram o palco onde se apresenta nossa missão, ou seja, quais devem ser as posições brasileira e argentina em termos estratégicos e seus reflexos em termos de segurança e política de defesa? Interpretá-las é esquadrinhar o palco apresentado nas suas duas vertentes centrais: o da submissão ao discurso hegemônico e o da sua contestação. Planejar a defesa não é trabalhar com probabilidades, é ir além, é trabalhar com possibilidades.

\section{2) A subordinação à hegemonia: abordagem atual da segurança e defesa no Brasil e na Argentina}

Estamos, hoje, muito mais próximos do quadrante da subordinação. No momento, as posições do Brasil e da Argentina são de Estados não perturbadores, algo que tem sua gênese na concepção econômica dos governos dos dois países. A situação não contestadora conduz a que os textos oficiais que tratam sobre a defesa de ambos os países deixem antever posições comportadas e conjugadas aos chamados princípios gerais dominantes (intervencionismo, globalização, direitos humanos, questões ecológicas, etc.) e, portanto, alinhadas à chamada democracia representativa e ao livre comércio. Contudo, estas posições são muito mais fortes na visão expressa no Libro Blanco de la Defensa Nacional de la Republica Argentina, editado em 1999, do que no texto da Política de Defesa Nacional, publicado pela Presidência da República do Brasil, em 1996. A posição brasileira se coloca de forma muito mais independente aos desígnios de Washington que a posição argentina. Contudo, ainda assim, poderia ser colocada no quadrante da não contestação, não pelo seu discurso mas, muito mais, pela sua prática. 
Comecemos analisando a posição brasileira pelo seu discurso. As diretrizes constantes no documento citado são as que se seguem:

“a. contribuir ativamente para a construção de uma ordem internacional, baseada no estado de direito, que propicie a paz universal e regional e o desnvolvimento sustentável da humanidade;

b. participar crescentemente dos processos internacionais relevantes de tomada de decisões;

c. aprimorar e aumentar a capacidade de negociação do Brasil no cenário internacional;

d. promover a posição brasileira favorável ao desarmamento global, condicionado ao desmantelamento dos arsenais nucleares e de outras armas de destruição em massa, em processo acordado multilateralmente;

e. participar em operações internacionais de manutenção de paz, de acordo com os interesses nacionais;

f. contribuir ativamente para o fortalecimento, a expansão e a solidificação da integração regional;

g. atuar na manutenção de um clima de paz e cooperação ao longo das fronteiras nacionais, e para a solidariedade na América Latina e na região do Atlântico Sul;

h. intensificar o intercâmbio com as Forças Armadas das nações amigas;

i. manter a participação das Forças Armadas em ações subsidiárias que visem à integração nacional, à defesa civil e ao desenvolvimento sócio-econômico do País, em harmonia com sua destinação constitucional;

j. proteger a Amazônia Brasileira, com o apoio de toda a sociedade e com a valorização da presença militar;

l. priorizar ações para desenvolver e vivificar a faixa de fronteira, em especial nas regiões norte e centro-oeste;

m. aprimorar a organização, o aparelhamento, o adestramento e a articulação das Forças Armadas, assegurando-lhes as condições, os meios orgânicos e os recursos humanos capacitados para o cumprimento da sua destinação constitucional;

n. aperfeiçoar a capacidade de comando, controle e inteligência de todos os órgãos envolvidos na defesa nacional, proporcionando-lhes condições que facilitem o processo decisório, na paz e em situação de conflito;

o. aprimorar o sistema de vigilância, controle e defesa das fronteiras, das águas juridicionais, da plataforma continental e do espaço aéreo brasileiros, bem como dos tráfegos marítimo e aéreo;

p. garantir recursos suficientes e contínuos que proporcionem condições eficazes de preparo das Forças Armadas e demais órgãos envolvidos na defesa nacional; 
q. fortalecer os sistemas nacionais de transporte, energia e comunicações;

r. buscar um nível de pesquisa científica, de desenvolvimento tecnológico e de capacidade de produção, de modo a minimizar a dependência externa do País quanto aos recursos de natureza estratégica de interesse para a sua defesa;

s. promover o conhecimento científico da região antártica e a participação ativa no processo de decisão de seu destino;

t. aprimorar o sistema de Mobilização para atender às necessidades do País, quando compelido a se envolver em conflito armado; e

u. sensibilizar e esclarecer a opinião pública, com vistas a criar e conservar uma mentalidade de Defesa Nacional, por meio do incentivo ao civismo e à dedicação à Pátria.”

O discurso, portanto, explicita, de forma clara, uma política comprometida com os interesses nacionais tradicionais do Brasil. Contudo, a prática difere do discurso e demonstra uma mudança, nos últimos anos, que busca um alinhamento com os ditames da hegemonia. Senão vejamos:

a) a recente criação do Ministério da Defesa, subordinando a política de defesa a uma instância civil que faz a mediação dos interesses militares com a esfera executiva do Governo o que é perfeitamente compatível com o modelo sugerido pela hegemonia nos chamados princípios de Williamsburg (1995). Desta forma, busca-se criar mais um mecanismo para afastar os militares brasileiros do processo decisório nos temas de Política Nacional;

b) a assinatura de diversos acordos, que se vinculam diretamente a uma política de defesa, que a diplomacia brasileira rejeitava, por ferir regras claras de simetria, como o TNP e o MCTR;

c) o sucateamento deliberado de uma promissora indústria de material de defesa e a perda do objetivo primordial de autonomia tecnológica por parte das autoridades governamentais;

d) a despreocupação com aspectos de logística e de mobilização ao longo do processo de privatização de empresas que formatam a infra-estrutura do país e a conexão deste processo a mecanismos de desterritorialização como o disposto no chamado Consenso de Washington;

e) a minimização orçamentária das Forças Armadas.

Já a Argentina, em seu Libro Blanco de la Defensa Nacional, apresenta de forma clara a sua quase inteira concordância com o discurso hegemônico ao vislumbrar, na Parte I daquela publicação, o que coloca como seu cenário estratégico. Ao estabelecer as ameaças, há uma perfeita coincidência com o disposto na cartilha do centro hegemônico: o narcotráfico; o crime organizado; o terrorismo; o fundamentalismo; a proliferação de armas massivas de destruição e seus vetores de lançamento; o contrabando de armas; as migrações decorrentes de limpezas étnicas ou por falta de espaços econômicos de sobrevivência. A coincidência não se dá só na paridade da moeda mas, também, no diagnóstico das 
ameaças. Há, contudo, uma clara e crescente tensão nos pressupostos no interior da concepção estratégica argentina, que opõe o seu contexto continental ao subregional e que se tem mantido, ainda, sem ruptura, exclusivamente, pela prática submissa de seu maior parceiro o Brasil, como foi colocado, ao núcleo hegemônico. Isto se reflete, no entanto, na impossibilidade ainda observada de ambos países estabelecerem uma agenda comum de princípios nas questões vinculadas à segurança.

1.3) A perturbação à hegemonia: outra abordagem da segurança e da defesa no Brasil e na Argentina

Imagine-se a possibilidade de um dos dois países, ou ambos, o que seria mais natural, fugirem ao controle de hegemonia e contestarem-na. Ou, então, o que teria a mesma conseqüência, a hegemonia, pela busca crescente da dominação no Hemisfério Ocidental, estabelecer unilateralmente pressões insuportáveis que conduzam necessariamente à contestação. Esta hipótese não deve ser abandonada na avaliação do tema proposto e deve merecer especial atenção por parte daqueles que estudam a problemática da defesa e da segurança, no Brasil e na Argentina. E isto agora deve ser feito em um ambiente pós-Kosovo, onde parece ter caído por terra o Artigo Segundo da Carta das Nações Unidas, que proíbe a ameaça do uso da força contra a integridade territorial e a independência política de qualquer Estado, e que estabelece o princípio da solução das controvérsias internacionais por meios pacíficos.

Aqui reside o cerne da questão. Segurança e política de defesa são questões de Estados e não de governos.

\section{2) Explicitação e análise das ameaças}

A maior das ameaças que pesa, hoje, sobre o Brasil e a Argentina é a da fragmentação do Mercosul, algo que representará a destruição do projeto comum de constituição de um pólo de poder na América do Sul com projeção mundial. Esta ameaça, se concretizada, seria um retrocesso para ambos os países, destruindo a perspectiva que eles têm de participar, de forma marcante, na arena mundial, e que os levaria a se perder em querelas entre si e questões internas do subcontinente.

A esta ameaça juntam-se outras, decorrentes dos aspectos prevalentes das ameaças detectadas, gestadas ou imaginadas pelo centro, tais como: crime organizado, narcotráfico, conservação dos silvícolas em seu estado primitivo, exploração predatória dos recursos naturais e tráfico ilegal de armas que, associado ao terrorismo ou a movimentos guerrilheiros, podem vir a criar as condições para sanções, inclusive militares, ações alienígenas nos nossos territórios ou em países 
vizinhos, ameaçando, portanto, a nossa soberania e a paz nesse espaço. Estas possibilidades de instabilidade são fatores de risco e necessitam de uma ação endógena de cunho policial, ou seja, de natureza interna e de uso do legítimo direito dos Estados de impor suas leis em seus territórios e incompatível, portanto, com a prática, que se quer generalizada, de ações intervencionistas do tipo OTAN, como polícia do mundo. Segurança envolve tanto prevenção e ação face aos choques intra-estatais, a defesa interna - algo que se processa no âmbito das soberanias dos Estados envolvidos -, quanto prevenção e ação face aos choques interestatais, que visam defender soberanias e vontades nacionais e que se conceituam como defesa externa. Misturar conceitos é atentar contra a ordem e a paz internacional.

Outra questão que permanece colocada é a questão da ocupação das ilhas do Atlântico que, primitivamente, foram ibéricas como nós, Argentina e Brasil. É o caso das Ilhas Malvinas, Geórgias do Sul, Sandwich do Sul, Tristão da Cunha, Santa Helena e Ascenção. Trata-se de focos permanentes de preocupação quanto ao seu destino.

Outra preocupação diz respeito ao destino da Antártida, cuja proximidade e contato com o subcontinente sul-americano merecem especial atenção quanto ao seu controle, soberania e segurança.

Portanto, as ameaças encontram-se em contenciosos que transcedem o subcontinente e alçam a questão estratégica para fora de seus limites no plano mundial. A América do Sul, ao final do século XX, retira-se com o Mercosul de seu próprio espaço e projeta-se no mundo. As questões de insegurança são novas, como novas têm de ser as concepções de defesa.

\section{3) Análise dos meios}

Estabelecido o quadro maior, é bom lembrar que política externa e a política de defesa são complementares e constituem dimensões fundamentais na vida do Estado. É através delas que o Brasil e a Argentina, como qualquer Estado, se relacionam com os demais Estados, explorando as possibilidades que se oferecem, no exterior, à satisfação das necessidades da nação. Ambas, política externa e política de defesa, se destinam à proteção dos próprios interesses do Estado e à defesa de sua integridade, ou seja, diplomacia e força são duas faces da mesma moeda que, ao longo da história das civilizações, sempre caminharam juntas, com prevalência ora de uma, ora de outra. As políticas externa e de defesa são função de diversos fatores, onde se destacam os de caráter geopolítico e os de caráter econômico.

É interessante ressaltar, também, ao se abordar o binômio política externa e política de defesa, que as conquistas ou a defesa de interesses vitais pela diplomacia só se viabilizam quando há, por trás dela, uma força capaz de respaldá-las; isto é, 
no mundo, mesmo em um contexto de "paz e cooperação", prevalecem os reclamos de países fortes e poderosos.

Cabe-nos aqui falar sobre as características passadas e presentes de cada um dos países analisados.

As dimensões do país e sua importância no seu espaço geográfico deram à política externa e à política de defesa do Brasil condicionantes claros. A extensa fronteira terrestre, a inexistência de questões fronteiriças, o caráter também ibérico de seus vizinhos, a meridionalidade de sua posição geográfica, a litoralidade atlântica, todos estes fatores se constituem em elementos mais proximamente indicadores de uma atuação internacional do Brasil e, portanto, das suas políticas externa e de defesa. Ao se debater estas políticas, também devem ser acrescidos a esses fatores de natureza geográfica outros, de natureza histórica e cultural, que se fizeram constituir no corpo de idéias que lastrearam e lastreiam a inserção internacional do Brasil.

Para tanto, faz-se necessário observar a atuação pretérita do Brasil no plano externo e quais as características que o distinguem no campo internacional.

O grau de previsibilidade de nossa política externa é dos mais elevados. Apesar de flutuações que resultaram de diferentes visões governamentais, constituiu-se no Brasil um corpo doutrinário de política externa, que assim resumiremos:

a) o Brasil sempre teve um caráter não confrontacionista. Defende o princípio da autodeterminação e seu corolário, a não-intervenção. Sempre foi a favor da solução pacífica de contenciosos e sempre condenou o uso da força para a obtenção de resultados externos. Tem índole pacífica que se explica por fatores sócio-culturais, tais como a defesa do território, a abundância de recursos naturais, a heterogeneidade cultural, a tolerância social e a tranqüilidade diante dos vizinhos; o Brasil não é belicoso, nem belicista;

b) o Brasil sempre foi juridicista. Sempre sacralizou os tratados ou as convenções, como se fossem manifestações irretocáveis da vontade nacional ou multilateral; e

c) o Brasil foi realista e tornou-se pragmático.

As modificações decorrentes de seu crescimento exigem que se explicite, agora, uma política de defesa para o Brasil, não só pelo pragmatismo mencionado, pelas ameaças acima mencionadas, mas, principalmente, por ter sido o país alçado a um plano de poder mais alto do que os seus vizinhos, o que o colocou em um espaço menos tranqüilo da arena internacional.

Já a Argentina, teve, ao longo deste século, uma política externa que privilegiava seus interesses mais imediatos. Nunca apresentou uma grande continuidade na sua política externa, culminando este imediatismo, que se refletia em uma imprevisibilidade, no episódio da reocupação das Ilhas Malvinas. Contudo, 
a partir deste episódio, a Argentina tem, consistentemente, conduzido uma política externa que privilegia seus vizinhos e tem buscado o diálogo e a estabilidade crescente na busca do aumento da confiança mútua e da cooperação em torno da segurança. A política externa atual busca transferir do âmbito regional para o mundial as questões que requerem uma política de defesa, algo que só faz sentido se esta política for praticada através de sistema de segurança coletivo, compartilhado e cooperativo.

Tentaremos contribuir para estas políticas, a brasileira e a argentina, com algumas proposições baseados, exclusivamente, nos meios de que dispomos. É importante para o entendimento das propostas, o conhecimento de alguns pressupostos básicos, que resultaram de nossas reflexões e que dizem respeito aos nossos meios e às nossas disponibilidades:

- $\quad$ primeiro, que, diferentemente do que tentam difundir, a alta tecnologia de armamento só traz a vitória em situações muito especiais, como a guerra do Golfo. Mesmo assim, tem os seus limites, como pode afirmar Saddam Hussein. Ou nem a vitória fácil trazem, como afirma agora Milosevic. Armas de alta tecnologia não trouxeram muita ajuda em lugares como o Vietnam ou a Somália, ou a agressão a Iugoslávia, onde diplomacia, resultante de uma liderança, nos parece que teria sido algo muito mais efetivo. Ao olhar a história, pode-se afirmar que o armamento sempre foi menos decisivo na guerra do que o moral das tropas. Isto sempre será verdade. O moral das tropas está cada vez mais associado a algo relativamente novo e que se conhece como opinião pública. A conquista desse espaço se faz pela permanente identificação do interesse público com o interesse nacional, algo que exige uma postura ativa por parte do beligerante. É bom sempre lembrar que, em clima de guerra, é o interesse nacional que estabelece o interesse público e não o contrário;

- $\quad$ segundo, que o desenvolvimento da tecnologia de armamento vinha sendo vagaroso ao longo da história. Séculos se sucediam sem que houvesse progressos significativos. Agora, isto se modificou. Novas famílias de armamento aparecem a cada década. O que está acontecendo com todas as mudanças que se vêm processando no modo de guerrear não é algo novo. Nova é a velocidade com que se vêm materializando essas mudanças. Entretanto, os retardatários chegam aos mesmos resultados gastando mil vezes menos, ou menos ainda. Olhando as últimas décadas, verifica-se que as nações ricas gastaram trilhões de dólares em satélites espaciais, mísseis intercontinentais e explosivos nucleares. Hoje, para se atingir os mesmos objetivos, gastar-se-ia mil ou mais vezes menos. Onde se gastou trilhões, gastar-se-ia bilhões, ou menos. Com o xerox, com o fax e com a Internet não há segredos. O que pode haver é mais falta de vontade política do que falta de recursos. Todavia, deve-se enfatizar que um mínimo de recursos financeiros 
é um fator chave para o sucesso. Sem ele não se pode ter tecnologia para melhores armamentos ou tropas mais bem treinadas. Uma nação pobre tem de fazer o melhor com seu parco orçamento, mas, em um confronto com uma nação rica, cabe lembrar que o dinheiro tende a falar mais alto do que boas intenções. Além do mais, a história recente dos países poderosos demonstra que o orçamento de defesa é aquela parcela que, dos gastos governamentais, tende a ser a maior fonte de desperdícios e de corrupção. Contudo, também, sempre é a fonte de maior poder político. Deve-se ter em mente, observando os orçamentos de defesa dos países ricos, que é comum, nesses países, armarem as tropas, não com o equipamento que necessitariam para cumprir seus objetivos, mas sim com aqueles dispositivos que foram julgados pelos interesses políticos mais úteis. Este erro é imperdoável para um país pobre;

- terceiro, como as recentes guerras demostraram, as forças armadas, hoje, podem ser de duas naturezas: as que nomearemos de intensivas em pessoal e aquelas que nomearemos de intensivas em material. As intensivas em pessoal são baratas, e mais adequadas aos países pobres, enquanto que as intensivas em material são caras, e mais adequadas aos países ricos. Também, forças armadas de índole ofensiva custam bem mais que forças armadas de índole defensiva. Forças armadas de índole defensiva têm naturalmente o predomínio das forças terrestres sobre as forças aéreas e navais, pois o caráter defensivo resulta da baixa capacidade de projeção de seu poder, por meios aéreos ou marítimos, para além de suas fronteiras. Contudo, não se pode prescindir de meios aéreos e navais que materializem o que se convencionou chamar de esforço combinado, tratando-se de países com as dimensões da Argentina e do Brasil que contam com teatros prováveis de operações que reúnem condições peculiares de emprego desses meios, como claramente são os casos da Patagônia e da Amazônia. Lá, avultam a necessidade da adequação das forças terrestres às suas condições peculiares, da modernização dos meios navais e do estabelecimento de sólidos e confiáveis sistemas de proteção aérea;

- $\quad$ quarto, dentro da força terrestre, a infantaria é a grande responsável pelo sucesso de uma postura defensiva. O sucesso da infantaria reside em dois pontos: primeiro, no grau de interação do combatente com a natureza que o cerca, e, segundo, com a adequabilidade de seu equipamento e de seu armamento a este meio ambiente. A adequabilidade do equipamento em nações pobres tem como um de seus maiores incentivadores a utilização crescente por parte da população rural de bens industriais. A atividade rural deve ser servida com uma indústria com capacidade de transformação para fins bélicos;

- quinto, em termos de guerra convencional, há uma revolução na guerra que ainda está por vir. A última foi a mecanização. A próxima será a dos armamentos antimecanização. Deve-se entender como armamentos 
antimecanização todos aqueles capazes de destruir, a um baixo custo relativo, os armamentos resultantes da mecanização tais como tanques, aviões e navios. Estes equipamentos já estão disponíveis com a atual tecnologia e, entre estes, destaque especial deve ser concedido aos mísseis guiados, em especial, àqueles portáteis e acessíveis ao infante;

- $\quad$ sexto, o binômio espaço-tempo sempre foi o elemento determinante para a condução da guerra. Hoje, o fator tempo está maximizado. O tempo é fundamental, tanto para quem defende como para quem ataca. A luta também é contra o relógio. Nas áreas geoestratégicas críticas, como é a Amazônia, ou a Patagônia, o seu habitante deve estar habilitado para, prontamente, assumir as missões de defesa do território. Esta é uma vantagem: a defesa não pode abrir mão do profundo conhecimento do terreno;

- $\quad$ sétimo, os gastos com a defesa devem ser diretamente relacionados com o valor das riquezas a serem preservadas. O Brasil e a Argentina figuram, hoje, como os detentores de riquezas construídas ou de riquezas naturais que os colocam entre os quinze mais ricos países do planeta. A média de gastos anuais destes quinze países, de acordo com dados colhidos no Instituto Internacional de Estudos Estratégicos em Londres e no Instituto de Relações Internacionais e Estratégicas de Paris, é de cerca de 3,5\% de seus produtos internos brutos (PIB). O Brasil gasta, de acordo com estas fontes, bem menos que isto, cerca de $1,8 \%$ do PIB, a Argentina 1,6\%, dados do ano passado, que nos parecem majorados; e

- $\quad$ oitavo, é falso o conceito difundido de que se processa, no momento, uma bem sucedida revolução dos assuntos militares, baseada no princípio do conhecimento e que despreza o conceito de massa numérica como elemento decisivo. Há uma glorificação mal-sucedida do conceito de softpower. Este conceito, que se apoia em três vertentes - o conjunto de informações estratégicas (o que explica a ênfase concedida a sensores não tripulados monitoradores de espaço), o processamento destas informações e a ação baseada no conhecimento destas informações (através de armamentos tidos como de precisão cirúrgica) e que se conceitua no C3I2 (comando, controle, comunicações, inteligência e informática) -, tem levado a resultados medíocres. Isto acontece, mesmo sem que a principal ameaça a este trato das questões militares (pelo viés único do princípio do conhecimento) tenha sido usada, ou seja, o ataque aos sistemas de informação que a suportam.

Observados esses pressupostos, verificamos deterem o conjunto dos dois países as condições necessárias e suficientes para prover os meios necessários a sua defesa. A questão está na conscientização do problema a ser enfrentado e na vontade para o emprego desses meios. Tudo converge para a vontade. Defesa como qualquer ato requer vontade. 


\section{4) Escolha da estratégia}

Como fruto de nossas reflexões caberia agora fazer a escolha de uma estratégia militar de defesa para o Brasil, para a Argentina e para o Mercosul, baseada na avaliação das vulnerabilidades dos possíveis inimigos e no ajustamento dos meios com os fins e isto nos conduz, inexoravelmente, para a escolha da Estratégia de Dissuasão, tão bem apresentada e defendida também pelo general Meira Mattos, no trabalho já referenciado para o Senado Brasileiro do qual retiramos os seguintes trechos, onde ela é mencionada: “A nossa estratégia de defesa mais aconselhada, em face deste tipo de ameaças, acreditamos, será a de dissuasão. No livro Introduction à la stratégie, o general francês André Beaufre, prefaciado por outro renomado estrategista, o inglês Liddell Hart, conceitua a estratégia de dissuasão como aquela em que 'o país visado procura evitar a ação bélica impondo uma ameaça que o agressor não possa ou não esteja disposto a pagar’.”

"Esta estratégia vem dando certo nos últimos conflitos em que países pequenos e médios, como a Somália e grupos armados na dividida ex-Iugoslávia, querendo evitar a intervenção militar em seus territórios, apresentam uma capacidade de resistência que os governos dos 'grandes' não podem pagar, sem se submeterem a um tremendo desgaste político perante a opinião pública de seus países. Há hoje, nas grandes democracias, uma verdadeira idiossincrasia ao envio de seus compatriotas a guerras exteriores, para lutar por causas que o povo não entende.”

Ainda com respeito a mesma estratégia, mas mais vocacionado agora para o teatro amazônico, algo perfeitamente aplicável também no teatro do extremo sul do continente, assim colocava, no texto referido, o general Meira Mattos: “A nossa estratégia para a Amazônia, portanto, deverá se apoiar na constante manifestação de firmeza do Governo e da diplomacia, repelindo qualquer intenção internacionalista, venha de onde vier, e na existência, ali, de uma força militar de dissuasão dispondo de armas e equipamentos modernos e de alta capacidade de treinamento para as ações na selva. Diz o escritor francês André Gluksmann (Le discours de la guerre) que a intenção da nação de resistir e a eficiência da força militar devem ser constantemente reveladas, para que o efeito de dissuasão se realize."

Apresenta-se, complementarmente, as seguintes recomendações para a explicitação, em diretrizes, de uma estratégia de ação diplomática e de defesa, que serve tanto para o Brasil, como para a Argentina, como para ambos:

a) a participação em fóruns de poder, como o Conselho de Segurança da ONU, faria muito mais sentido se os novos partícipes fossem dotados dos elementos de poder mais próximos daqueles com que contam os demais países que pertencem a este fórum. Sem poder, corre-se o risco de não se ver o seu voto ou veto respeitado, ou pior, de ter o seu voto ou veto condicionado pelo poder alheio. Por isso, não se pode abrir mão de ter-se o poder não convencional, a menos que os outros, que o 
detenham, abram mão dele, dentro de uma política de desarmamento não convencional, plena e irrestrita;

b) o conhecido binômio segurança-desenvolvimento necessita ser transformado em um trinômio, pela anexação do conceito de justiça social. Em decorrência do seu atual estágio de retardatários, está claro que, tanto o Brasil quanto a Argentina ainda deveriam priorizar seus gastos em desenvolvimento e assistência social vis à vis de seus gastos com a segurança. Em função dessa priorização, devem possuir forças armadas baratas. As forças armadas de ambos os países devem, portanto, ser intensivas em pessoal, o que afastaria, por critérios puramente técnicos, o término do serviço militar obrigatório. Devem, também, ser de índole defensiva o que prioriza claramente as forças terrestres e o equipamento a ser desenvolvido, fabricado e utilizado. Entretanto, o avanço no projeto de desenvolvimento de ambos os países tem de vir acompanhado, no campo do armamento convencional, de uma progressiva capacitação de projeção de poder e da maior participação orçamentária para desenvolvimento e construção conjunta de meios aéreos e navais, como adiante será apresentado;

c) a política de recrutamento deve privilegiar o conscrito da zona rural, em especial o morador da região amazônica ou patagônica, uma vez que deverão ser creditados a estas importantes áreas de ambos territórios, cerca de $50 \%$ das bases físicas, as prioridades dos planejamentos militares. A este deve ser dado o serviço militar em condições especiais próximas ao antigo tiro de guerra. O conscrito da zona rural deve ser treinado em operar o equipamento bélico na sua região. A retirada do conscrito da zona rural para o serviço militar em zonas urbanas ou sede de municípios tem sido responsável por parcela significativa do êxodo rural que, entre outras mazelas, diminui, inclusive, a capacidade de defesa territorial;

d) dentro das forças terrestres, ênfase especial deve ser concedida às operações na selva, principalmente, em razão do teatro amazônico. Neste espaço, a infantaria é que trafega com maior desenvoltura no teatro de operações e também é ali a de menor custo operativo e de melhor índice de custo-benefício;

e) deve-se considerar que é muito melhor para o defensor ter uma tropa permanentemente estabelecida na região a ser defendida, do que ter que deslocar tropa para lá, por mais rápido que seja o seu deslocamento. O conhecimento do terreno é uma vantagem extremamente relevante. Daí porque é importante se ter uma política de ocupação militar tanto para a Amazônia pelo Brasil quanto para a Patagônia pela Argentina;

f) é necessário conscientizar-se de que, por mais barata que seja a linha de ação adotada, ela, ainda assim, custa dinheiro. Se se objetiva mais segurança deve se ter mais recursos. Deve-se aumentar os gastos com forças armadas na Argentina e no Brasil, em termos de participação no PIB, de forma progressiva, até 3,5\%, que é o valor médio adotado pelos países de mesma grandeza relativa que a Argentina e o Brasil; 
g) a prioridade em termos de política industrial para a área de defesa, por um lado, deve estruturar, nos pequenos centros urbanos imersos na área rural, múltiplas indústrias voltadas para as necessidades de camping e do campo, e, por outro, nas áreas urbanas mais desenvolvidas do país, de indústrias que desenvolvam atividades civis e militares vinculadas a mísseis guiados, como miniaturização eletrônica e mecânica, propulsores, explosivos, cartografia digitalizada e outras tecnologias. Só com autonomia estratégica, ou seja, com capacidade de produzirmos o necessário para nos defender, é que tem sentido falar-se em política de defesa;

h) é de fundamental importância revalorizar-se no Mercosul a atividade militar. O militar deve ser visto como o cidadão em armas, o defensor da pátria e não como o responsável pelo arbítrio, como parcela da mídia tenta ainda infundir. Nenhuma nação retira o mito e aura que cercam a função militar impunemente. A opinião pública tem de entender e ver com bons olhos a função militar e a mídia tem um importantíssimo papel neste processo;

i) assim, também, é de fundamental relevância revalorizar-se a função do policial, defensor primeiro da ordem pública e da segurança interna e priorizar-se a aplicação da justiça; e,

j) finalmente, é preciso conscientizar o que foi colocado no início desta monografia: segurança é um estado, defesa é um ato. Segurança tem o culto, o educado, frente ao inculto, pois sabendo mais, tem mais condição de se defender melhor. Segurança tem o desenvolvido, pois tem mais meios para se defender. Segurança tem o mais rico, pois tem mais recursos para sustentar a sua defesa. Portanto, segurança é algo bem mais complexo e abrangente. Ao abandonar a terminologia, ao se envergonhar dela, tanto o Brasil como a Argentina cometem um grande erro, quaisquer que sejam as interpretações errôneas e exageros que possam ter ocorrido em percursos conjunturais do passado.

\section{5) Conclusões e recomendações}

Compomos Brasil e Argentina e os demais países do Mercosul ampliado, no momento, e com os demais países da América do Sul, em futuro próximo, um pólo de poder, dentro de uma concepção multifacetada, que não privilegia, exclusivamente, o viés geográfico e econômico, mas que contempla, também, na aglutinação que realizamos, aspectos culturais, políticos e sociais e apresenta, também, compatilhamento de princípios e de concepção estratégica. Esta composição, contudo, tem sido feita em época de transição do sistema mundial, o que tem aumentado o grau de imprevisibilidade na evolução da situação estratégica. É necessário, ao abordarmos o tema segurança e política de defesa, lembrarmos que a expectativa gerada por estes fatos e a vigília estratégica que se faz necessária requerem, também, uma polarização no campo militar. Esta polarização se dará 
naturalmente pela constituição de um pacto de defesa comum no âmbito do Mercosul ampliado e da América do Sul, no futuro. Urge, portanto, a montagem de um mecanismo comum de defesa: a Organização de Defesa do Mercosul.

Somos dois países pacíficos, mas somos grandes países que têm um projeto comum de constituição de uma ampla área de livre comércio e que querem cruzar o futuro vendo suas identidades nacionais e sua soberanias respeitadas. Se não assegurarmos um grau razoável de autonomia estratégica militar, não seremos mercedores do respeito dos aventureiros e ambiciosos que sempre existiram no mundo.

Em Ushuaia, colocou-se o Mercosul ampliado (Argentina, Bolívia, Brasil, Chile, Paraguai e Uruguai) como zona livre de armas de destruição massiva, já que a preocupação era de natureza endógena e esta colocação era vista como elemento essencial para a paz na região. Um pacto de defesa comum torna a questão de defesa como exógena e possibilita a revisão da questão das armas de destruição massiva, se a assimetria de poder, que a posse de tais armas traz, não for revogada do cenário mundial.

Ao sul do Equador, tanto o Oceano Atlântico como o Pacífico são espaços de interesse para o Mercosul e devem ser conceituados como zonas de paz. Portanto, devemos exercer claro controle nas passagens interoceânicas ao sul do Equador. O Canal de Beagle, a Passagem de Drake, o Estreito de Magalhães, o Cabo da Boa Esperança, o Pacífico Meridional, o Atlântico Sul e o estrangulamento do Atlântico, entre o nordeste do Brasil e o saliente da África, devem merecer especial atenção de nossas forças aéreas e navais.

Com o amplo espaço a ser defendido, portanto, tanto o Brasil como a Argentina têm de possuir um eficiente sistema integrado de vigilância com radares. Uma força terrestre de vigilância de toda a fronteira e marítima das extensas costas do subcontinente e aérea em ambos os espaços se faz necessária, que disponha de um sistema eficiente de apoio de comunicações e transportes, bem como uma massa de reserva, que contenha uma parcela estratégica de curto emprego e de alta mobilidade e que esteja localizada em área central do nosso espaço continental e que deverá ter a capacidade de atender, rapidamente, a qualquer emergência.

Para o futuro próximo, os nossos compromissos com a ONU e a OEA obrigam-nos a manter forças adequadas e preparadas para as missões de paz, que tendem a ser cada vez mais freqüentes. A proteção de nosso espaço aéreo não pode ser descuidada: a tendência é aumentarem as ameaças de violação. Isto justifica a montagem de programas conjuntos de desenvolvimento e fabricação de mísseis e de aeronaves de combate e de transporte. Nosso imenso litoral e águas territoriais exigem uma força naval eficiente. O espaço marítimo a ser controlado requer a montagem de um sistema que permita a projeção conjunta de poder sobre esta vasta área. O desenvolvimento de forças de superfície e de submarinos para 
este espaço justifica o aparelhamento de estaleiros em ambos os países de forma a prover autonomia estratégica.

O nosso maior objetivo, repetimos, no futuro, deve ser o de aumentar a nossa autonomia estratégica. Cumpre, portanto, reativar as indústrias de ambos os países, voltadas direta ou indiretamente para a aplicação militar, e os centros de pesquisas a elas vocacionados.

Finalmente, sintetizando tudo o que foi dito, a nossa prospectiva para a defesa do Brasil e da Argentina vê como ameaças principais, no futuro, as decorrentes de pressões internacionalistas, de fora do subcontinente sul-americano, que se anunciam como cada vez mais intensas, abrigando idéias de desrespeito à soberania nacional. Não se pode desprezar a preocupação com que essas pressões venham a contar com o apoio militar ostensivo ou velado de uma ou mais potências do chamado primeiro mundo, como ocorreu mais recentemente no episódio da Iugoslávia. Esta ameaça é, pelos indícios de que dispomos, nossa maior ameaça exógena. Endogenamente, todavia, existe a ameaça sempre presente de nos dividirem para nos submeterem.

Como diz o já mencionado estrategista francês André Gluksmann, a maior vulnerabilidade dos chamados grandes está na opinião pública de seus países, que rejeita, hoje, a hipótese de participação em guerras distantes, em terras desconhecidas, por causas que não entende. Contudo, para que esta vulnerabilidade seja potencializada, é mister que o país ameaçado de intervenção ofereça uma visível disposição de reagir pelas armas e revele possuir forças armadas capazes de vender caro sua derrota, desencorajando, assim, a expectativa de uma fácil vitória, sem sacrifícios de vida e de pesados ônus materiais. É a chamada estratégia de dissuasão ou dissuasão estratégica.

Todavia, para se manter um alto grau de ameaça dissuasória três coisas são indispensáveis:

- vontade nacional comum de defender a nossa soberania territorial;

- a existência de uma convincente força militar combinada (terrestre, naval e aérea); e

- autonomia estratégica.

A vontade nacional de resistir deve ser cultivada pelo estímulo à educação cívica em ambos os países. A juventude precisa ser reeducada no sentido de deter em alto grau orgulho nacional. Nossas diplomacias, em todos os fóruns, devem fazer ver e afirmar esta vontade.

A força militar combinada dissuasória terá de revelar sua capacidade de durar na luta. Para isso, em termos de guerra convencional, teremos de apresentar, visivelmente, efetivos treinados e bem armados capazes de durar no combate, mesmo enfrentando adversários muito mais poderosos.

O armamento e o equipamento destinados a esta força dissuasória deverão ser fabricados nos dois países, tanto quanto possível, dentro de um planejamento 
conjunto, a fim de evitar embargos internacionais ao cumprimento de sua missão de defesa. A força dissuasória, para ser efetiva e durar na luta, precisará dispor de autonomia estratégica, isto é, capacidade operativa e autonomia logística.

É bom lembrar que a disponibilidade de armas não convencionais fortalecerá sempre a ação diplomática. Não faz sentido falar em desarmamento unilateral. Isto só faz sentido para aqueles que perderam o entendimento das questões mundiais e acreditam em terminologia e discursos fabricados, sem nenhum respaldo racional, e ditos como sendo politicamente corretos. Se acordos nos proíbem, individualmente, de deter armas de destruição de massa, nada nos impede de forma conjunta, ou seja, no âmbito do Mercosul, de desenvolvê-las, caso o desarmamento pretendido, em âmbito mundial, fique, para sempre, na retórica.

Finalizando, face ao quadro internacional de incertezas que vislumbramos para o futuro, temos de mostrar, claramente, que somos capazes de vender caro a nossa soberania. Se assim o fizermos, sem dúvida, seremos capazes de preservar incólumes nossos patrimônios nacionais e a nossa identidade ibérica.

Junho de 1999

\section{Notas}

1 O texto visa a trazer novos subsídios aos estudos sobre o tema e expressa exclusivamente opiniões do autor, e não, necessariamente, as das entidades a qual pertence.

2 Página 23 da obra traduzida que teve como título em português EUA X JAPÃO Guerra à vista, Editora Nova Fronteira.

\section{Bibliografia}

ABC. Quem é quem no Mercosul. Brasilia: Ministério de Relações Exteriores, 1995.

ABREU, Florêncio Sérgio Lima. Área Hemisférica de Livre Comércio. Brasília: Ministério de Relações Exteriores, 1993.

ALMEIDA, A. J. (Org.). MERCOSUL Integração e Impacto Socioeconômico. Petrópolis: Editora Vozes, 1997.

ALMEIDA, P. R. MERCOSUL: Textos Básicos. Brasília: Fundação Alexandre de Gusmão, 1992.

BRANDÃO, A.S. e PEREIRA, L. V. MERCOSUL Perspectivas de Integração. Rio de Janeiro: Fundação Getúlio Vargas, 1996.

BRAUDEL, Fernand. Civilização Material, Economia e Capitalismo, Volume I - As Estruturas do Cotidiano (1986). São Paulo: Martins Fontes Editora, 1996.

- Civilização Material, Economia e Capitalismo, Volume II - O Jogo das Trocas (1986). São Paulo: Martins Fontes Editora, 1996.

—. Civilização Material, Economia e Capitalismo, Volume III - O Tempo do Mundo (1986). São Paulo: Martins Fontes Editora, 1996.

BRZEZINSKI, Zbiginiew. Out of Control: Global Turmoil on the Eve of the Twenty-First Century. New York: Scribner, 1993.

CEPAL. Estudio económico de América Latina y el Caribe-1996-1997. Santiago: Naciones Unidas, 1997. 
CERVO, A. L. e BUENO, C. História da Política Exterior do Brasil. São Paulo: Editora Ática, 1992. CLAUSEWITZ, Carl. Da Guerra (1832-1834). Brasília: Martins Fontes, 1979.

COSTA, Darc. Brasil Defesa do Estado. Rio de Janeiro: CEBRES, 1997.

GADDIS, John Lewis. Strategies of Containement : A Critical Appraisal of Postwar American National Security Police. New York: Oxford University Press, 1982.

GILPIN, R. The Political Economy of International Relations. Princeton: Princeton University Press, 1987.

GONÇALVES, Reinaldo et al. A Nova Economia Mundial. Rio de Janeiro: Editora Campus, 1998.

HEGEL, G. W. F. Principes de la Plilosophie do Droit (1821). Paris: Gallimard, 1940.

—_. Introdução à Filosofia da História (1837). Rio de Janeiro: Editora Tecnoprint, 1986.

—_. Enciclopédia das Ciências Filosóficas em Epítome, (volumes I a III). Lisboa: Edições 70 Lda, 1992.

—. A Razão na História (1817). Lisboa: Edições 70 Lda, 1992.

HIRST, M. Argentina-Brasil: Perspectivas Comparativas y Ejes de Integratión. Buenos Aires: Editorial Tesis, 1990.

HOBBES, T. Leviatã (1651). São Paulo: Abril Cultural, 1974.

HUMPHREYS, R. A. The Evolution of Modern Latin America. Oxford: Clarendon Press, 1946.

HUNTINGTON, Samuel P. The Clash of Civilizations and the Remaking of World Order. New York: Simon and Schuster, 1996.

IPSO- Instituto de Projetos e Pesquisas Sociais e Tecnológicas (Organização). A Causa Nacional -O Futuro da Nação Brasileira. São Paulo: Editora Senac, 1998.

JAKOBSON, Roman e Outros Autores. Língua, Discurso e Sociedade. São Paulo: Global Editora. KENNAN, George F. American Diplomacy, 1900-1950. Chicago: University of Chicago, 1951.

KENNEDY, Paul. The Rise and Fall of the Great Powers: Economic Change and Military Conflit, 1500-2000. New York: Random House, 1987.

KISSINGER, Henry. Diplomacy. New York: Simon and Schuster, 1994.

LIMA REGO, Elba Cristina. O Processo de Constituição do MERCOSUL. Rio de Janeiro: BNDES, Fevereiro-1995.

LIST, F. Sistema Nacional de Economia Política, Coleção Os Economistas. São Paulo: Abril Cultural, 1983.

LODGE, J. The European Community and the Challenge of the Future. London: Pinter, 1993.

MACE, G. e THÉRIEN, J. P. Foreign Policy \& Regionalism Americas. London: Lynne Rienner Publishers, 1991.

MALGRIDA, Carlos Badia. El Factor Geografico en La Politica Sudamericana. Madrid: Establecimiento Tipografico de Jaime Ratés, 1919.

MAURO, Frederic. Do Brasil a América. São Paulo: Perspectiva S.A., 1975.

MEIRA MATTOS, C. A Geopolítica e as Projeções de Poder. Rio de Janeiro: José Olympio Editora, 1977.

—_. Uma Geopolítica Pan-Amazônica. Rio de Janeiro: José Olympio Editora, 1980.

- Geopolítica e Trópicos. Rio de Janeiro: Biblioteca do Exército, 1984.

MERCOSUL - Textos Básicos. Brasília: Fundação Alexandre de Gusmão, (Coleção Integração Regional I), 1992.

MORGENTHAU, Hans J. In Defense of the National Interest: A Critical Examination of American Foreign Policy. New York: Knopf, 1951.

MORSE, R. M. O Espelho do Próspero - Cultura e Idéias nas Américas. São Paulo: Editora Schwarcz Ltda, 1995.

MYLTEKA, L. K. South-South Co-operation in a Global Perspective. Paris: OECD, 1992.

NIEBUHR, R. e HEIMERT A. A Nation so Conceived. New York: Charles Scriber's Sons, 1963.

OHMAE, Keiniche. The Boardless World, Power and Strategie in the Interlinked Economy. NewYork: Harper Perennial, 1991. 
— De L'État-Nation aux États-Régions. Paris: Dunod, 1995.

OMAN, C. Globalization and Regionalization, The Challenge for Developing Countries. Paris: OECD, 1994.

ORGANIZATION DES NATIONS UNIES (ONU). Étude sur l'économie mundiale. New York: United Nations, 1992.

PARLATINO. Cuadernos del Parlatino n. 5, Seminario Mercosur-Venezuela. São Paulo: Editora do Parlatino, 1995.

POITRAS, G. The Ordeal of Hegemony. The United States of Latin America. Boulder: Westview Press, 1990.

RAMONET, Ignacio. Geopolítica do Caos. Petrópolis: Editora Vozes, 1998.

RAPOSO, Amerino. Dimensões da Estratégia (volumes I e II). Rio de Janeiro: BIBLIEX, 1992.

REICH, Robert. O Trabalho das Nações. São Paulo: Educator, 1993.

RUFIN, J. C. L'Empire et les Noveaux Barbares. Paris: Éditions Jean Claude-Lattés, 1991.

RUSSELL, R. La politica exterior argentina en el nueva ordem mundial. Buenos Aires: FLACSO/ GEL, 1992.

SCHWEIZER, Peter. Victory. New York: The Atlantic Monthly Press, 1994.

SENADO FEDERAL DO BRASIL. Profecias. 1996.

SHANAHAN, E. W. South America: An Economy and Regional Geography. London: 1963.

SOMBART, Werner. L'Apogeé du Capitalisme (1928). Paris: Gallimard, 1932.

SPYKMAN, Nicholas J. America's Strategy in World politics: The United States and the Balance of Power. New York: Harcourt, Brace, 1942.

STRANGE, S. States and markets. New York: Basil Blackwell, 1988.

TOURAINE, Marisol. Le Bouleversement du Monde Geopolitique du XXIe Siécle. Paris: Editions du Seuil, 1995.

TUlCHIN, J. La Argentina y los Estados Unidos: Historia de una desconfiança. Buenos Aires: Editora Planeta, 1990.

VAYSSIÈRE, Pierre. L'Amérique Latine de 1890 à nos jours. Paris: Hachette Supérieur, 1996.

ZEA, Leopoldo. Fuentes de la Cultura Latinoamericana. México: Fondo de Cultura Económica, 1995.

\section{Resumo}

O artigo começa apresentando uma análise da atual configuração do poder no cenário internacional, dividido entre centro (hegemônico e não hegemônico) e periferia (e suas subdivisões), para, em seguida, traçar um panorama das percepções estratégicas de cada uma das subdivisões do sistema internacional em sua relação com o Brasil, a Argentina e o Mercosul, em especial. Ao final, o artigo analisa a situação corrente e prescreve iniciativas tocantes às políticas de defesa e segurança definidas como ideais para Brasil, Argentina e o Mercosul.

\section{Abstract}

The article presents an analysis of the current configuration of power in the international scenario, divided between the center (hegemonic and not 
hegemonic) and the periphery (and its subdivisions). At length, a panorama of strategic perceptions of each of the subdivisions of the international system, especially in its relation with Brazil, Argentina and Mercosul, is traced. At the end, the article analyses the current situation and prospects for defense and security policies of Brazil, Argentina and Mercosul.

Palavras-chave: Política de defesa. Política de segurança. Brasil. Argentina. Mercosul.

Key-words: Defense policy. Security policy. Brazil. Argentina. Mercosul. 